\title{
Modelo petrofísico del borde oriental de las sierras de Valle Fértil-La Huerta, Argentina, a partir de datos sísmicos y petrológicos
}

\author{
Ma. Florencia Ahumada ${ }^{1}$, Brígida Castro de Machuca $^{2,3}$, Patricia Alvarado², \\ Jean-Baptiste Ammirati² y María Gimena López ${ }^{2}$
}

${ }^{1}$ Instituto de Investigaciones en Energías No Convencionales - Consejo Nacional de Investigaciones Científicas y Técnicas, Unidad de Recursos Geológicos y Geotérmicos. Universidad Nacional de Salta, Av. Bolivia No. 5150, C.P. 4400, Salta, Argentina.

${ }^{2}$ Departamento de Geofísica y Astronomía, Centro de Investigaciones de la Geósfera y la Biósfera -

Consejo Nacional de Investigaciones Científicas y Técnicas, Facultad de Ciencias Exactas, Físicas y Naturales, Universidad Nacional de San Juan, Meglioli No. 1160 S Rivadavia, C.P. 5400, San Juan, Argentina.

${ }^{3}$ Instituto de Geología, Facultad de Ciencias Exactas, Físicas y Naturales, Universidad Nacional de San Juan,

Meglioli No. 1160, C.P. 5400, San Juan, Argentina.

*ahumadaflor@hotmail.com

\section{RESUMEN}

Este trabajo es una contribución al conocimiento de la estructura cortical del sector oriental de las sierras de Valle Fértil-La Huerta (Sierras Pampeanas Occidentales, San Juan, Argentina) a los $31^{\circ} \mathrm{S}$, en la región del antepaís del orógeno andino en el segmento donde la placa de Nazca subduce horizontalmente a $\sim 100 \mathrm{~km}$ de profundidad. Se confeccionó un modelo de velocidades 1D, combinando estudios petrográficos y sismológicos a partir del análisis de 19 muestras de rocas ígneas y metaígneas plutónicas del arco magmático famatiniano (Ordovícico), que componen la mayor parte del basamento cristalino de dichas sierras. Las litologías granitoides predominan en la región norte, y las máficas en el sur. El análisis sismológico consistió en modelar funciones del receptor en los sitios donde afloran estas rocas a partir de telesismos que fueron registrados por tres estaciones sismológicas: LUNA, MAJA y CHUC. Así, fue posible obtener las velocidades de ondas P y S (Vp, Vs) y el coeficiente de Poisson ( $v$ ), entre otros parámetros elásticos. El modelo de velocidades sísmicas indica una corteza engrosada con un espesor promedio entre 55 y $60 \mathrm{~km}$ con respecto a promedios globales $(\sim 41 \mathrm{~km})$; este promedio es consistente con la hipótesis de eclogitización parcial de la corteza inferior. La presencia de dos discontinuidades en las velocidades sísmicas intracorticales en niveles de corteza media ( 12 y $28 \mathrm{~km}$ de profundidad) podría asociarse a zonas de despegue (décollements), donde su extensión lateral estaría relacionada con la acreción del terreno Cuyania al terreno Pampia. Se han determinado valores bajos de velocidades de onda $\mathrm{P}$ $(\mathrm{Vp} \sim 5.8 \mathrm{~km} / \mathrm{s})$ y $\mathrm{Vp} / \mathrm{Vs}(\sim 1.70)$ para niveles de corteza superior, consistentes con litologías granitoides y velocidades de ondas P elevadas (Vp $6.76 \mathrm{~km} / \mathrm{s}), \mathrm{Vp} / \mathrm{Vs}(\sim 1.78)$ para niveles de corteza inferior, homologables con litologías máficas de mayor densidad $\left(\sim 3.00 \mathrm{~g} / \mathrm{cm}^{3}\right)$ con respecto a otras regiones del retroarco andino. Estos valores son consistentes con la existencia de rocas máficas compuestas por olivino, orto- y clinopiroxeno que constituyen la raíz del arco magmático famatiniano. Los resultados indican condiciones metamórficas de alto grado y profundidades correspondientes a propiedades geofísicas de niveles de corteza media a inferior, y se correlacionan con la hipótesis de un manto deshidratado, frío y enriquecido en magnesio que se encontraría en la zona comprendida entre la placa de Nazca subducida y la base de la corteza del terreno Cuyania.

Palabras clave: modelo petrofísico; basamento cristalino; subducción horizontal; Sierras Pampeanas Occidentales; Argentina.

\section{ABSTRACT}

This paper is a contribution to the knowledge of the crustal structure of the eastern flank of the Valle Fértil - La Huerta ranges (Western Sierras Pampeanas, San Juan, Argentina) at $31^{\circ} \mathrm{S}$, in the Andean foreland region, where the Nazca plate is subducting horizontally at about $100 \mathrm{~km}$ depth. A $1 D$ velocity model was constrained, combining petrographic and seismological observations from analysis of 19 igneous and metaigneous plutonic rocks belonging to the Famatinian (Ordovician) magmatic arc, which make up most of the crystalline basement of these ranges. Granitoid lithologies predominate in the northern region whereas mafic lithologies are more common to the south. The seismological analysis consisted of modeling teleseismic receiver functions near three seismological stations: LUNA, MAJA and CHUC, in places where those rocks are dominant. Thus, $P$ and $S$ seismic-wave velocities (Vp and $V s)$ and Poisson's coefficient ( $v)$, among other elastic parameters, were obtained. The seismic velocity model indicates an overthickened crust with an average thickness between 55 and $60 \mathrm{~km}$, which matches with global average values $(\sim 41 \mathrm{~km})$; this agrees well with the hypothesis of partial eclogitization in the lower crust. The presence of two seismic velocity discontinuities at mid-crustal levels (12 and $28 \mathrm{~km}$ depths), likely associated to décollements, might be related to the accretion of the Cuyania terrane to the Pampia terrane. We obtained low P seismicwave velocities (Vp $5.8 \mathrm{~km} / \mathrm{s}), V p / V s$ ratio $(\sim 1.70)$ in upper crust levels consistent with granitoid lithologies, as well as high $P$ seismic-wave velocities $(V p \sim 6.76 \mathrm{~km} / \mathrm{s}), \mathrm{Vp} / \mathrm{Vs}$ ratio $(\sim 1.78)$ in lower crust levels; these

Ahumada, M.F., Castro de Machuca, B., Alvarado, P., Ammirati, J.-B., López, M.G., 2017, Modelo petrofísico del borde oriental de las sierras de Valle Fértil-La Huerta, Argentina, a partir de datos sísmicos y petrológicos: Revista Mexicana de Ciencias Geológicas, v. 34, núm. 1, p. 1-11. 
figures match with mafic lithologies of a more dense $\left(\sim 3.00 \mathrm{~g} / \mathrm{cm}^{3}\right)$, lower crust with respect to other back-arc Andean regions. Also, these values are consistent with the existence of mafic rocks composed of olivine, orthoand clinopyroxene, which constitute the root of the Famatinian magmatic arc. These results indicate high-grade metamorphic conditions and depths corresponding to geophysical properties of middle to lower crust and correlate with the hypothesis of a dehydrated, cool and magnesiumenriched mantle located in the region between the subducted Nazca slab and the bottom of the Cuyania terrain crust.

Key words: petrophysical model; crystalline basement; flat slab subduction; Western Sierras Pampeanas, Argentina.

\section{INTRODUCCIÓN}

En el presente trabajo se dan a conocer los resultados de la integración de análisis petrográficos y sismológicos llevados a cabo en las distintas litologías que caracterizan al borde oriental de las sierras de Valle Fértil-La Huerta (SVF-LH), a lo largo de una transecta longitudinal de $60 \mathrm{~km}$ de extensión en dirección NW-SE, aproximadamente a $\operatorname{los} 31^{\circ} \mathrm{S}$ (Figura 1). Estas sierras pertenecen a la unidad morfoestructural de Sierras Pampeanas Occidentales (Caminos, 1979) e integran las Sierras Pampeanas del centro-oeste de Argentina que afloran desde los $25^{\circ} 30^{\prime}$ hasta los $33^{\circ} \mathrm{S}$, una zona de aproximadamente $900 \mathrm{~km}$ en sentido N-S y $400 \mathrm{~km}$ en sentido E-W. Las mismas se caracterizan por presentar un estilo estructural de bloques limitados principalmente, en su flanco occidental, por fallas inversas lístricas, reactivadas recientemente por la orogenia andina (González Bonorino, 1950; Jordan y Allmendinger, 1986; Baldo et al., 1997; Rapela et al., 2001). A partir de la observación geofísica y la caracterización de las principales litologías aflorantes, se determinó la estructura de corteza y manto superior bajo las SVF-LH con base en sus velocidades sísmicas de ondas $\mathrm{P}(\mathrm{Vp})$ y S (Vs). Específicamente, el trabajo consistió en el reconocimiento y recolección in situ de 24 muestras representativas de las litologías que componen el basamento cristalino para su análisis petrográfico y microestructural. En forma simultánea se midieron parámetros geofísicos utilizando ondas sísmicas registradas por tres estaciones sismológicas (LUNA, MAJA, CHUC) del experimento SIEMBRA (Sierras Pampeanas Experiment using a Multicomponent Broadband Array, Gans et al., 2011). Se determinó la composición modal de 19 muestras seleccionadas y los resultados de este análisis, se procesaron siguiendo la metodología de Hacker y Abers (2004). Se estimaron las propiedades físicas Vp, Vs, densidad $(\rho)$, coeficiente de Poisson $\left(\nu=\varepsilon_{\text {trans }} / \varepsilon_{\text {long }}\right.$, que indica la relación entre la deformación transversal $\left(\varepsilon_{\text {trans }}\right)$ y la paralela $\left(\varepsilon_{\text {long }}\right)$ al eje de un cuerpo cuando se le aplica una carga) y porcentaje de agua $\left(\mathrm{H}_{2} \mathrm{O}\right)$. Luego se compararon estos datos con valores de referencia para una amplia variedad de tipos litológicos compilados por esos autores. Las propiedades físicas resultantes del análisis petrofísico fueron posteriormente correlacionadas con valores de Vp y Vs proporcionados por el análisis sismológico. Estos valores corresponden a estructuras litosféricas de velocidades sísmicas obtenidas a partir de funciones del receptor bajo cada una de las estaciones sismológicas del experimento SIEMBRA que las registró (Fig. 1), siguiendo la metodología que se detalla en Ammirati et al. (2015).

El modelo cortical resultante integra la información petrológica y sismológica para auscultar la corteza en distintos niveles de profundidad y compararla, de noroeste a sureste, bajo las SVF-LH y con otros sectores del retroarco andino.

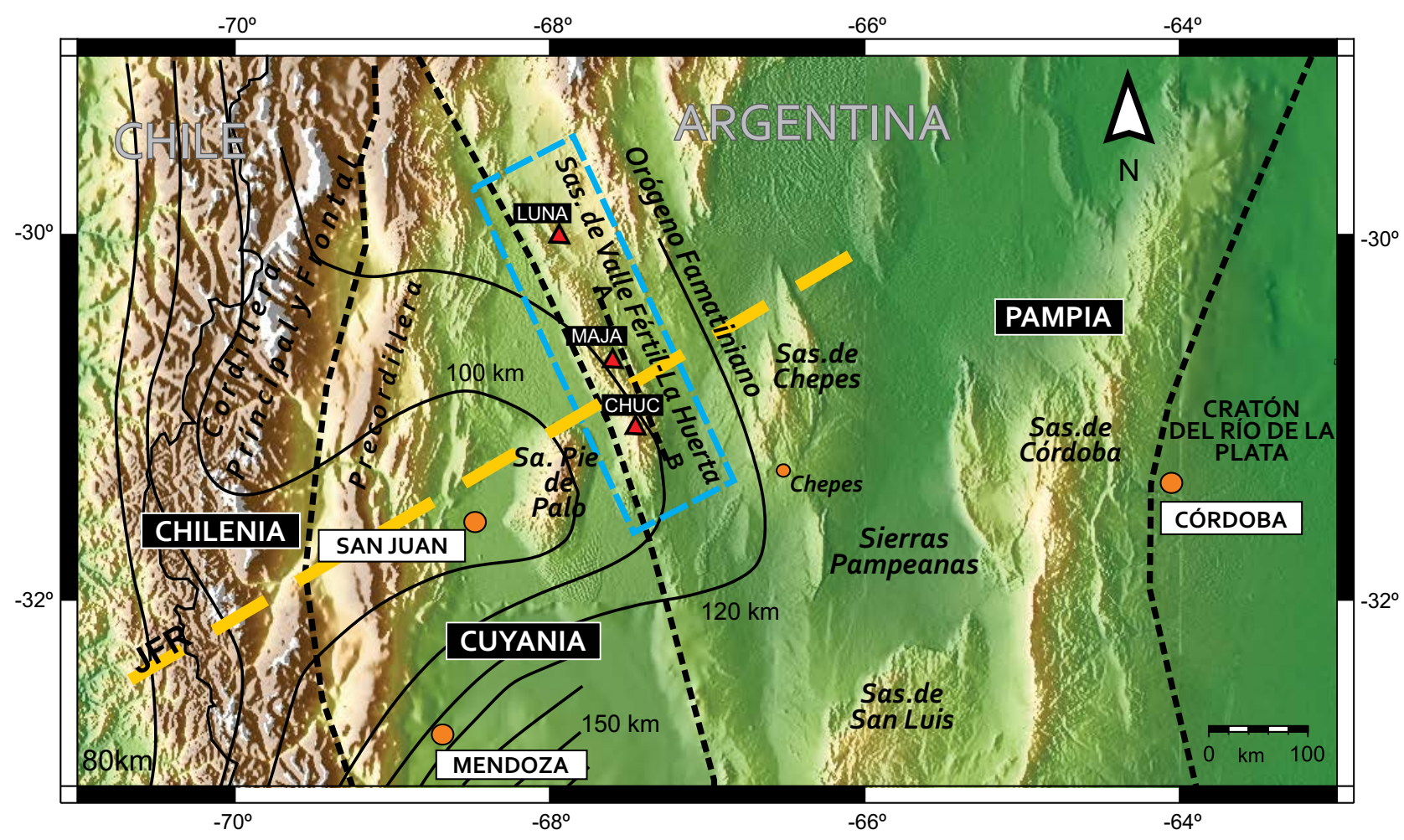

Figura 1. Principales unidades morfoestructurales, terrenos acrecionados contra el cratón Río de La Plata (Ramos et al., 2002; Rapela et al., 2007) y contornos de profundidad al tope de la placa oceánica subducida (Anderson et al., 2007). El rectángulo en línea discontinua indica la región de estudio (véase Figura 2), los triángulos representan estaciones sismológicas del experimento SIEMBRA utilizadas para la determinación de un modelo 1D de velocidades sísmicas y sitios de muestreo petrológico. La línea discontinua amarilla representa la subducción de la Dorsal de Juan Fernández (JFR) en proyección bajo el continente (Yañez et al., 2001). 


\section{MARCO GEOLÓGICO}

La zona de estudio forma parte de la unidad morfoestructural de Sierras Pampeanas desarrollada por la acreción de diferentes terrenos alóctonos y parautóctonos (Terreno Pampia, Rapela et al., 1998; Terreno Cuyania, Ramos, 1995; Ramos et al., 1998; Vujovich et al., 2004) durante el Proterozoico tardío y el Paleozoico temprano, amalgamados contra el protomargen de Gondwana (Astini y Thomas, 1999; Ramos et al., 2002; Ramos, 2010; Steenken et al., 2004; Miller y Söllner, 2005). Las Sierras Pampeanas Occidentales, en el sector de las SVF-LH, se caracterizan por un basamento compuesto por metamorfitas y migmatitas con una edad de metamorfismo ordovícica que alojan una serie de cuerpos intrusivos correspondientes a un arco magmático que se desarrolló durante la Orogenia Famatiniana entre el Ordovícico temprano y el Ordovícico medio (490 - 460 Ma, Tibaldi et al., 2009 y referencias allí insertadas). La composición de estos intrusivos varía desde gabros toleíticos a tonalitas y granodioritas asociadas a subducción y culmina con granitos poscolisionales de edad ordovícica tardía a devónica temprana (Ramos, 1988). Algunos granitos postectónicos se emplazaron durante el Carbonífero temprano. De acuerdo con Ramos (1988), este basamento corresponde a un orógeno del Paleozoico temprano. Actualmente, las Sierras Pampeanas Occidentales son parte del antepaís del orógeno andino de la placa Sudamericana, y su exposición y nivel de erosión están vinculados con la posición horizontal de la placa de Nazca que subduce a unos $100 \mathrm{~km}$ de profundidad, siendo parte del margen de subducción compresivo (Barazangi e Isacks, 1976; Cahill e Isacks, 1992; Anderson et al., 2007; Gans et al., 2011; Ammirati et al., 2015), con una velocidad de convergencia de $6.7 \mathrm{~cm} /$ año en dirección acimutal de $78^{\circ}$ (Kendrick et al., 2003; Vigny et al., 2009).

Las SVF-LH, entre $30^{\circ}$ y $31.5^{\circ} \mathrm{S}$, y $67^{\circ}$ y $68^{\circ} \mathrm{W}$, conforman una unidad orográfica de basamento preandino orientada en dirección aproximada NNW-SSE (Figura 1). Están constituidas por metamorfitas para- y orto-derivadas de alto grado de metamorfismo (gneises metapelíticos, migmatitas, mármoles y metabasitas hornbléndicas), intrusionadas por granodioritas, tonalitas, dioritas y gabros calcialcalinos metalumínicos, y por pegmatitas graníticas tardías (Mirré, 1976; Baldo et al., 1997; Rapela et al., 2001) (Figura 2). Tanto las unidades metamórficas como las ígneas, han experimentado deformación en franjas restringidas de cizallamiento dúctil con generación de milonitas (Castro de Machuca et al., 2005, 2008, 2012a). Este complejo cristalino pertenece al cinturón orogénico Famatiniano (Ordovícico), que se extiende de norte a sur, entre la Precordillera por el oeste y el orógeno Pampeano (Cámbrico) por el este, y que actualmente constituye el antepaís (Otamendi et al., 2006) (Figura 1). El levantamiento del orógeno Famatiniano durante su emplazamiento en la corteza superior podría ser relacionado, en primera instancia, a la colisión entre un terreno alóctono separado de Laurentia y el margen occidental de Gondwana, que alcanzó su clímax en el Ordovícico Medio (Thomas y Astini, 1996; Ramos et al., 1996). La edad silúrica temprana (438.7 \pm 1.9 Ma método Ar/Ar en anfíbol, edad meseta) para la cizalla en el este de la Sierra de La Huerta (Castro de Machuca et al., 2012a) representaría un estadio tardío y/o final de esta colisión.

El borde oriental de las SVF-LH está constituido casi exclusivamente por rocas intrusivas (granodioritas y tonalitas principalmente en la porción norte, y dioritoides y metagabros en el sector sur). Esta particularidad lo diferencia de las zonas central y occidental de las sierras donde hay afloramientos más extensos de paragneises y migmatitas. Por encima del complejo del basamento, sobre el borde occidental, se asientan en discordancia sedimentitas continentales gruesas asignadas al Triásico. A este mismo período se atribuyen las escasas rocas volcánicas (basaltos, traquibasaltos, traquitas y fonolitas) agrupadas en una única asociación alcalina continental no-orogénica (Mirré, 1976).
En el borde oriental, en parte sobre el basamento y en parte sobre las vulcanitas triásicas, se encuentran escasos y delgados paquetes de areniscas, limolitas y arcillitas cenozoicas de aproximadamente $30 \mathrm{~m}$ de espesor (Mirré, 1976). A ambos lados del cordón serrano se extienden depósitos del primer nivel de agradación y paleodunas de probable edad pleistocena y otros de edad reciente, que incluyen depósitos de piedemonte, médanos, limos, arcillas y aluviones actuales (Mirré, 1976).

Como resultado de los esfuerzos tectónicos pasados y actuales, las SVF-LH constituyen un bloque cristalino de aproximadamente $140 \mathrm{~km}$ de largo por $30 \mathrm{~km}$ de ancho que está siendo elevado diferencialmente por la tectónica andina (González Bonorino, 1950; Jordan y Allmendinger, 1986; Ortiz et al., 2014, 2015). La falla principal que eleva el bloque serrano coincide, a escala regional, con la megafractura de Valle Fértil (Baldis et al., 1990), la cual se extiende a lo largo del borde occidental de las sierras (Snyder et al., 1990; Zapata y Allmendinger, 1996; Zapata, 1998; Ortiz et al., 2015). Datos de gravimetría indican la existencia de una discontinuidad en la cuenca del río Bermejo que

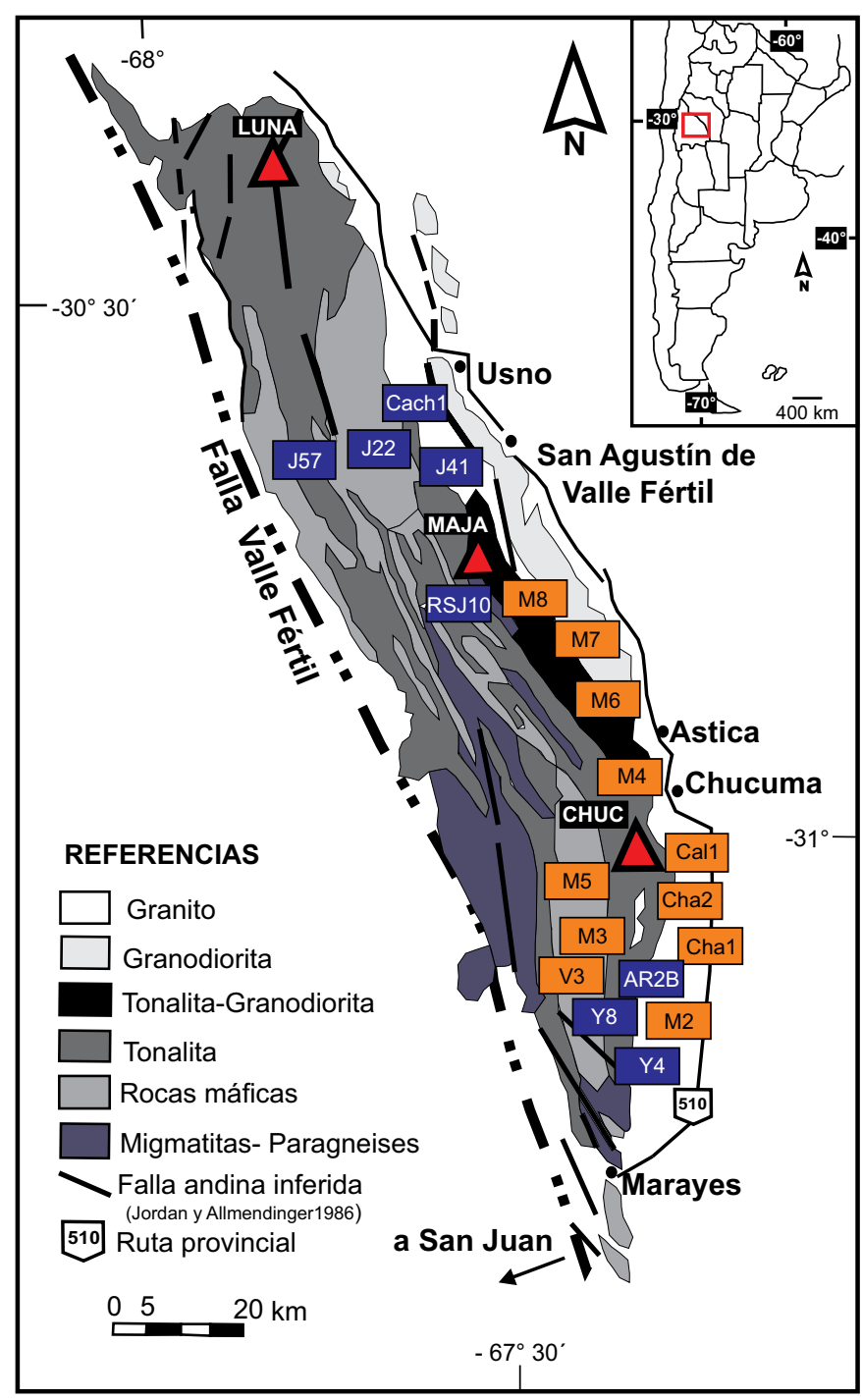

Figura 2. Mapa geológico simplificado de las sierras de Valle Fértil y La Huerta (basado en Otamendi et al., 2009), indicando la localización del muestreo petrográfico para rocas granitoides (en naranja) y máficas (en violeta). El respectivo análisis geofísico se resume en las Tablas 1 y 2 . También se muestra las estaciones sismológicas (triángulos) del proyecto SIEMBRA (véase también Figura 1). 
flanquea las sierras por el oeste (Giménez et al., 2000; Lince et al., 2008), la cual correspondería con la megafractura de Valle Fértil sugerida como el límite entre el terreno aloctóno derivado de Laurentia y el margen autóctono de Gondwana (Thomas y Astini, 1996; Ramos et al., 1996). Los estudios regionales de corteza que incluyen la zona bajo estudio, proponen distintas propiedades geofísicas para el sector occidental (terreno Cuyania), de aquellas observadas hacia el este, en el terreno Pampia de naturaleza más granítica, con ambos sectores en contacto a través de la citada megafractura (Alvarado et al., 2007).

\section{METODOLOGÍA}

El objetivo de este trabajo es el análisis simultáneo de datos petrológicos y sismológicos; por este motivo, los sectores de muestreo correspondieron con aquéllos donde se observaron formas de ondas sísmicas registradas por estaciones de banda ancha del experimento sismológico SIEMBRA distribuidas en las SVF-LH (Figuras 1 y 2). Así, se llevó a cabo el reconocimiento de campo y toma de muestras georeferenciadas de las litologías más representativas del basamento, tanto en la zona de emplazamiento de las estaciones sismológicas como en sus inmediaciones, en un radio de aproximadamente $25 \mathrm{~km}$. Se procedió al análisis macroscópico de las mismas con lupa binocular y, de un total de 24 muestras recolectadas a lo largo del borde oriental de las sierras, se seleccionaron aquéllas menos alteradas macroscópicamente, y que representan las distintas litologías aflorantes y sus variaciones texturales y composicionales. Como resultado, se obtuvieron 19 muestras, de las cuales se confeccionaron secciones delgadas, observándose cuidadosamente sus aspectos mineralógicos y microestructurales con un microscopio petrográfico de polarización. Con la ayuda de un contador de puntos semiautomático y del programa Counter PC 1.0 (Zippi, 1992), se determinó la abundancia volumétrica (moda) de los minerales componentes de las rocas expresada en porcentaje, con un promedio de $\sim 1000$ puntos contados en cada muestra, lo que permitió su clasificación petrográfica precisa. Los resultados del análisis modal se procesaron siguiendo la metodología de Hacker y Abers (2004) para estimar propiedades físicas, comparando los datos composicionales obtenidos con una amplia variedad de rocas comunes en márgenes compresivos. Este conjunto incluye 25 basaltos tipo MORB (Mid-Ocean Rift Basalts), 19 peridotitas hidratadas (diez harzburgitas y nueve lherzolitas) y 21 peridotitas anhidras (diez lherzolitas, siete harzburgitas, una dunita, una wherlita, una clinopiroxenita olivínica y una pirolita). Así, se estimaron Vp, Vs, densidad ( $\rho$ ) y coeficiente de Poisson ( $v$ ). Las condiciones de presión y temperatura (P-T) que se asumieron para las rocas bajo estudio corresponden a aquellas del pico de metamorfismo de $6.1 \pm 1 \mathrm{~kb}$ y $805 \pm 35^{\circ} \mathrm{C}$ estimadas por Otamendi et al. (2008). Las velocidades de ondas sísmicas que se obtienen representan zonas profundas de la corteza y dependen de las litologías que se observan en superficie. Otra etapa de este estudio consistió en comparar estos resultados con otras bases de datos petrológicos a nivel global (Zandt y Ammon 1995; Christensen y Mooney 1995; Christensen, 1996; Brocher, 2005; Marot et al., 2014). Estos autores compilaron velocidades de ondas sísmicas Vp, Vs, $\rho$ y $v$ para una amplia variedad de litologías comunes que se encuentran en diferentes niveles de corteza y ambientes geotectónicos, integrando además observaciones y mediciones de laboratorio y de campo. Sus trabajos proporcionan valores promedio para los parámetros geofísicos y rasgos característicos a profundidades litosféricas para diferentes composiciones mineralógicas, los cuales se consideran como un marco de referencia para este trabajo.

También se obtuvieron perfiles de velocidades sísmicas-profundidad utilizando funciones del receptor de telesismos (terremotos a más de $3000 \mathrm{~km}$ de distancia epicentral), calibrados con información de ondas superficiales, de manera de resolver con mayor resolución las mediciones a escala de corteza y manto superior bajo las tres estaciones sísmicas de las SVF-LH (Figuras 1 y 2).

Los valores de los parámetros geofísicos obtenidos a partir de las observaciones petrográficas-petrológicas, se compararon y correlacionaron con estimaciones de velocidades sísmicas resultantes del modelado de formas de ondas bajo las SVF-LH, lográndose un modelo final para la zona. Este modelo se compara con los estudios de Gallardo (2011) para esta zona y de otros autores para zonas aledañas de las Sierras Pampeanas Occidentales (Alvarado et al., 2007; Perarnau et al., 2010; Castro de Machuca et al., 2012b; Venerdini et al., 2016).

\section{ANÁLISIS PETROGRÁFICO}

El análisis petrográfico consistió en la caracterización y clasificación de las rocas mediante la observación directa en el terreno, y su posterior estudio petrográfico macro- y microscópico.

Las muestras recolectadas se dividieron en dos grupos (Figura 3):

- Rocas de composición granitoide que incluyen granitos/granodioritas (muestras M2, M5, Cha2, V3 y Cal1) y tonalitas/metatonalitas (muestras M3, M4, M6, M7, M8 y Cha1) (Figuras 2 y 3). Éstas afloran principalmente en el tramo central-septentrional de la transecta $A B$, en los alrededores de la localidad de Chucuma y hacia el norte (Figura 1). Se caracterizan por ser rocas con trama granuda a foliada plana, de color rosa naranja pálido a gris claro, y de grano medio a grueso. La foliación observada se debe al estiramiento de los minerales félsicos y a la orientación de las micas. Poseen textura equigranular alotriomórfica a hipidiomórfica, en transición a granoblástica; los componentes esenciales, feldespato potásico (ortoclasa y/o microclina), cuarzo y plagioclasa, se presentan en proporciones muy variables según el tipo litológico. Localmente se encontraron texturas micrográficas. Los minerales máficos están representados por hojas de biotita y, excepcionalmente, muscovita. El mineral accesorio más común es circón y a veces se observa granate, apatito, pistacita/clinozoisita y titanita, así como minerales opacos en muy escasa proporción.

- Rocas máficas que comprenden metagabros y metagabros olivínicos con textura de corona (muestras Y4, Y8, J22, Cach1, J57 y AR2B), anfibolitas (muestra RSJ10) y granulitas máficas (muestra J41) (Figuras 2 y 4). Las rocas gabroides están ampliamente distribuidas en las SVF-LH, en particular en el extremo austral (Figura 1). Se caracterizan por ser de color negro y grano grueso a muy grueso, con grandes cristales de minerales máficos. Suelen presentar aspecto moteado con máculas ferruginosas debido a la alteración diferencial de estos últimos. La mineralogía está representada por piroxeno y anfíbol, como fases principales, con olivino y plagioclasa cálcica (labradoritaanortita). Algunas rocas preservan estructuras (layering) y texturas ígneas relictas (granulares alotriomórficas a hipidiomórficas). Como resultado de las reacciones entre minerales durante el metamorfismo de alto grado, muchas desarrollaron texturas de coronas de ortopiroxeno (hiperstena) rodeando núcleos de olivino. Otras veces las coronas están compuestas por capas sucesivas de ortopiroxeno, clinopiroxeno y, más externamente, anfíbol verde pálido con intercrecimientos simplectíticos de espinela verde (hercinita). También se observa grandes cristales de piroxeno con inclusiones de olivino y de anfíbol con inclusiones de piroxeno. La espinela es el mineral accesorio dominante junto con muy escasa biotita, apatita, titanita y magnetita.

Con base en la caracterización petrográfica, se determinaron las respectivas composiciones modales. Asumiendo las condiciones de P-T de Otamendi et al. (2008) y la metodología de Hacker y Abers (2004), se obtuvieron velocidades Vp y Vs $(\mathrm{km} / \mathrm{s})$, densidad $\rho\left(\mathrm{g} / \mathrm{cm}^{3}\right)$, módulo de compresibilidad $\mathrm{K}$ (bulk modulus) (GPa), módulo de cizalla $\mathrm{G}$ (shear 

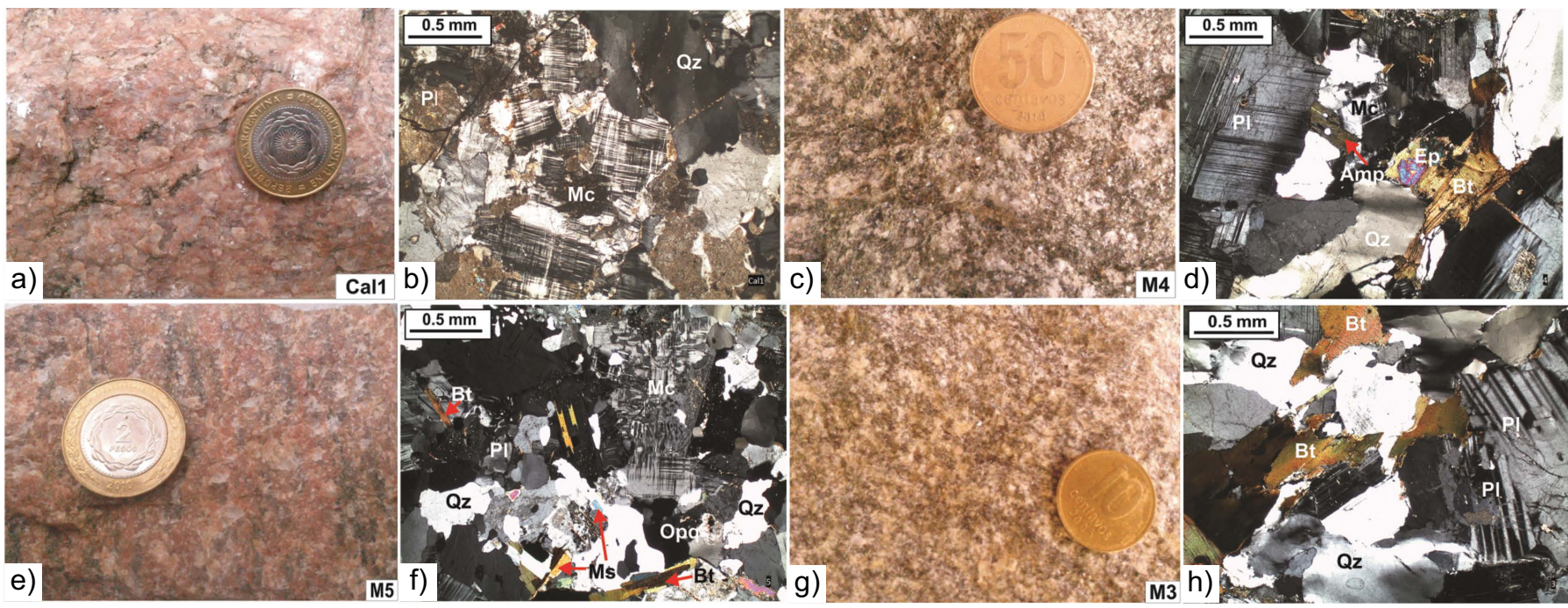

Figura 3. Fotografías de afloramiento y fotomicrografías (con nícoles cruzados) de algunas litologías graníticas incluidas en la Tabla 1 (muestras Cal1, M3, M4 y M5) y en la Fig. 2; a-b) granito; c-d) tonalita; e-f) granito y g-h) metatonalita. Referencias: Qz: cuarzo, Pl: plagioclasa, Mc: microclina, Amp: anfíbol, Bt: biotita, Ep: epidota, Ms: muscovita, Opq: minerales opacos.

modulus) (GPa), coeficiente de Poisson $v$ y porcentaje de agua $\left(\mathrm{H}_{2} \mathrm{O}\right)$, que se resumen en las Tablas 1 y 2. También se han comparado con valores obtenidos por otros autores para litologías similares en otras regiones del mundo (Figura 5).

\section{ANALISIS SISMOLÓGICO}

La técnica de función del receptor (Langston, 1979) usa datos de la sismicidad mundial registrada en la zona de estudio (SVF-LH) en cada sismómetro de tres componentes. Debido a la gran distancia epicentral comprendida entre 3000 y $10000 \mathrm{~km}$, los rayos sísmicos arriban al sismómetro con incidencia casi vertical y se ven afectados por la estructura debajo del receptor (Figura 6a). Al atravesar verticalmente una discontinuidad en velocidades sísmicas, se genera una conversión de onda $\mathrm{P}$ a onda $\mathrm{S}$. Las ondas $\mathrm{S}$ viajan a menor velocidad, por lo tanto, se registra una separación en tiempo de la fase de la onda $\mathrm{P}$ directa y la onda $\mathrm{S}$ convertida, la cual está directamente relacionada con los parámetros elásticos de la estructura que generó esa conversión. Invirtiendo funciones del receptor, se puede obtener la estructura en velocidades sísmicas debajo de las SVF-LH. Se ha observado que esta técnica sólo es sensible a cambio de velocidades relativas entre dos capas, lo cual genera dependencia del resultado al modelo de velocidades inicial. Por este motivo, si se agrega información de dispersión de ondas superficiales para invertir conjuntamente con funciones del receptor, es posible obtener valores absolutos mejorados de velocidades sísmicas.

De este modo, para cada una de las estaciones de la red SIEMBRA que están localizadas en la zona de estudio (Figura 2), Valle de la Luna (LUNA), La Majadita (MAJA) y Chucuma (CHUC), se invirtió conjuntamente los datos de funciones del receptor con datos de dispersión (velocidad de fase) de ondas de Rayleigh, según la metodología descrita en Ammirati et al. (2015). Así, las funciones del receptor han sido calculadas a partir de telesismos registrados durante el experimento SIEMBRA, entre 2007 y 2009 (Figura 7a). Un total de 18, 23 y 33 funciones del receptor fueron seleccionadas, respectivamente para las estaciones LUNA, MAJA y CHUC.

Ammirati et al. (2015) mostraron una estimación de la dispersión de velocidad de fase para las ondas Rayleigh en la zona de las Sierras Pampeanas Occidentales. A partir de los registros de ondas Rayleigh para cinco telesismos (Figura 7a) en cada estación, se remueve la respuesta instrumental y se realiza un análisis de filtros múltiples (Herrmann, 1973) que permite aislar el modo de vibración fundamental de las ondas superficiales para periodos de $10 \mathrm{~s}$ a $100 \mathrm{~s}$ y así descartar la contaminación por las ondas de cuerpo y modos de vibración secundarios. Una técnica de apilamiento de los datos de dispersión en el dominio de la frecuencia (McMehan y Yeldin, 1981; Mokthar et al., 1988) permite obtener una curva de dispersión de la velocidad de fase "promedio" para las Sierras Pampeanas, la cual fue utilizada en el presente trabajo.

En este análisis conjunto se invierte simultáneamente los datos de funciones del receptor (Figura $7 \mathrm{~b}$ ) con los datos de dispersión de la velocidad de fase (Figura 7c) utilizando el código joint96 (Julià et al., 2000; Herrmann y Ammon, 2002). Para cada una de las tres estaciones mencionadas se obtuvo un modelo de velocidad unidimensional hasta una profundidad de $150 \mathrm{~km}$ (profundidad máxima alcanzada por un periodo de 100 s). Un ejemplo se muestra en la Figura 7d para el modelo obtenido para la estación MAJA.

En la Figura 6b se presenta el modelo de velocidades sísmicas aproximado a escala litosférica para las SVF-LH. El mismo corresponde al promedio de los tres modelos obtenidos para las estaciones localizadas en el Valle de la Luna (LUNA), La Majadita (MAJA) y Chucuma (CHUC) (Figuras 1 y 2).

\section{DISCUSIÓN}

De los resultados que se resumen en las Tablas 1 y 2, y en la Figura $6 \mathrm{~b}$, se observa que las velocidades sísmicas presentan variaciones para diferentes niveles de la corteza. Estas variaciones corresponden con las diferencias en la composición mineralógica de las rocas analizadas y con el grado de metamorfismo que han experimentado. A lo largo del cordón montañoso de las SVF-LH se aprecian variaciones litológicas. A partir de la localidad de Chucuma (Figura 2) hacia el sur, predominan las rocas intrusivas dioríticas y fundamentalmente gabroicas, hasta niveles de cumulados ultramáficos, las que constituyen la "raíz" del arco famatiniano. Hacia el norte de esa localidad, hay un predominio de paragneises y migmatitas para-derivadas $y$, entre las rocas del complejo ígneo famatiniano, abundan las de composición intermedia 


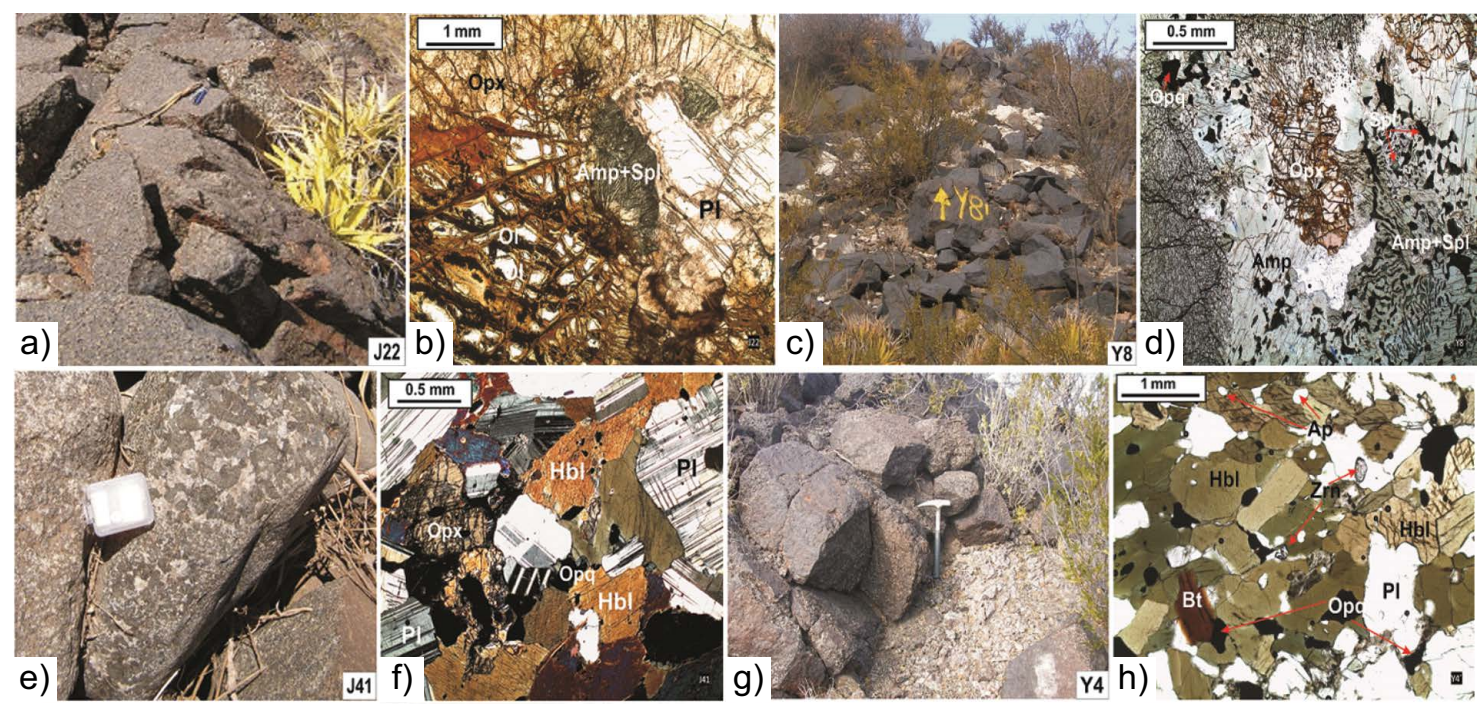

Figura 4. Fotografías de afloramiento y fotomicrografías (con nícoles paralelos, excepto F con nícoles cruzados) de algunas litologías máficas incluidas en la Tabla 2 (muestras J22, J41, Y4 y Y8) y en la Figura 2; a-b) y c-d) Metagabros olivínicos con textura de corona; e-f) granulita máfica con desarrollo localizado de porfiroblastos de anfíbol; g-h) metagabro. Referencias: Pl: plagioclasa, Opx: ortopiroxeno, Ol: olivino, Amp: anfíbol, Spl: espinela, Hbl: hornblenda, Opq: minerales opacos, Ap: apatita; Zrn: circón.

a félsica (tonalitas, granodiorita, granitos). En sectores de corteza media, el gradiente de velocidades aumenta, lo que está de acuerdo con un incremento en el grado de metamorfismo y una disminución en el contenido de sílice. Los valores hallados en las rocas granitoides, indican velocidades Vp entre $5.62 \mathrm{~km} / \mathrm{s}$ y $5.93 \mathrm{~km} / \mathrm{s}$, Vs entre $3.26 \mathrm{~km} / \mathrm{s}$ y $3.54 \mathrm{~km} / \mathrm{s}$, densidades entre $2.59 \mathrm{~g} / \mathrm{cm}^{3}$ y $2.77 \mathrm{~g} / \mathrm{cm}^{3}$, coeficiente de Poisson entre 0.20 y 0.26 y relación $\mathrm{Vp} / \mathrm{Vs}$ entre 1.62 y 1.75 , asumiendo condiciones de presión y temperatura correspondientes al pico de metamorfismo $\left(6.1 \pm 1 \mathrm{~kb}\right.$ y $805 \pm 35^{\circ} \mathrm{C}$ Otamendi et al., 2008). Estos valores están en concordancia con los valores estimados por Zandt y Ammon (1995), Christensen y Mooney (1995) (Figura 4), Christensen (1996) y Brocher (2005) para rocas de corteza superior. Para las rocas gabroides los valores de Vp varían entre $5.97 \mathrm{~km} / \mathrm{s}$ y $7.64 \mathrm{~km} / \mathrm{s}$, Vs entre $3.29 \mathrm{~km} / \mathrm{s}$ y $4.32 \mathrm{~km} / \mathrm{s}$, densidad entre $2.69 \mathrm{~g} / \mathrm{cm}^{3}$ y $3.50 \mathrm{~g} / \mathrm{cm}^{3}$, coeficiente de Poisson entre 0.27 y 0.29 y la relación $\mathrm{Vp} / \mathrm{Vs}$ entre 1.73 y 1.83 , con las mismas condiciones de presión y temperatura. La comparación con los valores obtenidos por los autores antes mencionados indica rocas de corteza media a inferior. Los valores que se consignan en este trabajo son representativos de rocas de corteza, tomando en cuenta que los valores de corteza promedio de Vp y Vs son de $6.45 \mathrm{~km} / \mathrm{s}$ (Christensen y Mooney, 1995) y $3.75 \mathrm{~km} / \mathrm{s}$ (Brocher, 2005), respectivamente; además Vp en el manto superior se estima en $8.09 \mathrm{~km} / \mathrm{s}$ (Christensen y Mooney, 1995). Según Zandt y Ammon (1995) y Christensen (1996) la densidad promedio de la corteza es de $2.66 \mathrm{~g} / \mathrm{cm}^{3}$ aumentando a $3.10 \mathrm{~g} / \mathrm{cm}^{3}$ en el manto superior, siendo nuestros datos mayores que estos valores. El coeficiente de Poisson para rocas graníticas se incrementa de 0.24 a 0.29 cuando disminuye el contenido de sílice y aumenta el grado de metamorfismo (Christensen, 1996). La relación Vp/Vs promedio para la corteza continental y oceánica, según Christensen (1996), suele ser entre 1.768 y 1.871, respectivamente; los valores promedios obtenidos por nuestro estudio para rocas de la corteza continental de la SVF-LH se hallan dentro de este rango.

El análisis sismológico para el sector analizado de las SVF-LH (Figura 6b), pone en evidencia dos discontinuidades en velocidades

Tabla 1. Rocas graníticas analizadas cuya localización se observa en la Figura 2, y propiedades físicas estimadas según Hacker y Abers (2004). P: presión; T: temperatura; $\mathrm{H}_{2} \mathrm{O}$ : agua; $\rho$ : densidad; Vp: velocidad de onda P; Vs: velocidad de onda S; K: módulo de compresibilidad (bulk modulus); G: módulo de cizalla (shear modulus); v: coeficiente de Poisson; Vp/Vs: relación entre Vp y Vs. Condiciones P-T asumidas según Otamendi et al. (2008).

\begin{tabular}{|c|c|c|c|c|c|c|c|c|c|c|c|}
\hline \multirow{2}{*}{$\begin{array}{l}\text { Litología } \\
\text { Muestra }\end{array}$} & \multicolumn{5}{|c|}{ Granito/Granodiorita } & \multirow{2}{*}{$\frac{\text { Metatonalita }}{\text { M3 }}$} & \multicolumn{5}{|c|}{ Tonalita } \\
\hline & M2 & M5 & Cha2 & Call & V3 & & M4 & M6 & M7 & M8 & Chal \\
\hline $\mathrm{P}(\mathrm{GPa})$ & 0.6 & 0.6 & 0.6 & 0.6 & 0.6 & 0.6 & 0.6 & 0.6 & 0.6 & 0.6 & 0.6 \\
\hline $\mathrm{T}\left({ }^{\circ} \mathrm{C}\right)$ & 805 & 805 & 805 & 805 & 805 & 805 & 805 & 805 & 805 & 805 & 805 \\
\hline \multicolumn{12}{|c|}{ Propiedades físicas calculadas con el promedio Hashin-Shtrikman } \\
\hline $\mathrm{H}_{2} \mathrm{O}(\%)$ & 0.3 & 0.4 & 0.1 & 0.0 & 0.0 & 0.4 & 0.3 & 0.2 & 0.7 & 0.1 & 0.1 \\
\hline$\rho\left(\mathrm{g} / \mathrm{cm}^{3}\right)$ & 2.68 & 2.69 & 2.60 & 2.60 & 2.59 & 2.73 & 2.70 & 2.69 & 2.77 & 2.68 & 2.60 \\
\hline $\mathrm{Vp}(\mathrm{km} / \mathrm{s})$ & 5.84 & 5.70 & 5.89 & 5.91 & 5.93 & 5.72 & 5.76 & 5.73 & 5.66 & 5.77 & 5.89 \\
\hline Vs $(\mathrm{km} / \mathrm{s})$ & 3.44 & 3.31 & 3.36 & 3.38 & 3.39 & 3.40 & 3.41 & 3.48 & 3.30 & 3.54 & 3.36 \\
\hline $\mathrm{K}(\mathrm{GPa})$ & 49 & 48 & 51 & 51 & 51 & 47 & 48 & 45 & 48 & 44 & 51 \\
\hline $\mathrm{G}(\mathrm{GPa})$ & 32 & 29 & 30 & 30 & 30 & 31 & 31 & 32 & 30 & 34 & 29 \\
\hline $\begin{array}{l}\text { Coeficiente de } \\
\text { Poisson }(v)\end{array}$ & 0.23 & 0.25 & 0.26 & 0.26 & 0.26 & 0.24 & 0.23 & 0.21 & 0.24 & 0.20 & 0.26 \\
\hline $\mathrm{Vp} / \mathrm{Vs}$ & 1.69 & 1.72 & 1.74 & 1.74 & 1.74 & 1.71 & 1.68 & 1.64 & 1.71 & 1.62 & 1.75 \\
\hline
\end{tabular}


Tabla 2. Rocas máficas analizadas cuya localización se observa en la Figura 2, y propiedades físicas estimadas según Hacker y Abers (2004). Condiciones P-T asumidas para el pico de metamorfismo según Otamendi et al. (2008). Véanse abreviaturas en la leyenda de la Tabla 1.

\begin{tabular}{|c|c|c|c|c|c|c|c|c|}
\hline \multirow{2}{*}{$\begin{array}{l}\text { Litología } \\
\text { Muestra }\end{array}$} & \multirow{2}{*}{$\begin{array}{c}\begin{array}{c}\text { Granulita } \\
\text { máfica }\end{array} \\
\text { J41 }\end{array}$} & \multirow{2}{*}{$\begin{array}{c}\begin{array}{c}\text { Metagabro } \\
\text { olivínico }\end{array} \\
\mathrm{J} 22\end{array}$} & \multicolumn{2}{|c|}{ Metagabro } & \multicolumn{2}{|c|}{ Metagabro coronítico } & \multirow{2}{*}{$\begin{array}{c}\begin{array}{c}\text { Gabro } \\
\text { olivínico }\end{array} \\
\text { Cach1 }\end{array}$} & \multirow{2}{*}{$\begin{array}{c}\text { Anfibolita } \\
\text { RSJ10 }\end{array}$} \\
\hline & & & Y4 & $\mathrm{J} 57$ & Y8 & $\mathrm{AR} 2 \mathrm{~B}$ & & \\
\hline $\mathrm{P}(\mathrm{GPa})$ & 0.6 & 0.6 & 0.6 & 0.6 & 0.6 & 0.6 & 0.6 & 0.6 \\
\hline $\mathrm{T}\left({ }^{\circ} \mathrm{C}\right)$ & 805 & 805 & 805 & 805 & 805 & 805 & 805 & 805 \\
\hline \multicolumn{9}{|c|}{ Propiedades fisicas calculadas con el promedio Hashin-Shtrikman } \\
\hline $\mathrm{H}_{2} \mathrm{O}(\%)$ & 0.9 & 0.2 & 0.3 & 0.3 & 1.2 & 1.2 & 0.5 & 1.3 \\
\hline$\rho\left(\mathrm{g} / \mathrm{cm}^{3}\right)$ & 2.84 & 3.11 & 2.69 & 2.69 & 3.11 & 3.10 & 3.00 & 3.50 \\
\hline $\mathrm{Vp}(\mathrm{km} / \mathrm{s})$ & 6.29 & 7.64 & 5.97 & 5.97 & 7.64 & 6.92 & 7.64 & 6.04 \\
\hline Vs $(\mathrm{km} / \mathrm{s})$ & 3.43 & 4.32 & 3.29 & 3.29 & 4.32 & 3.86 & 4.32 & 3.36 \\
\hline $\mathrm{K}(\mathrm{GPa})$ & 68 & 104 & 57 & 57 & 87 & 87 & 104 & 67 \\
\hline $\mathrm{G}(\mathrm{GPa})$ & 33 & 58 & 29 & 29 & 46 & 46 & 58 & 36 \\
\hline $\begin{array}{l}\text { Coeficiente de } \\
\text { Poisson }(v)\end{array}$ & 0.29 & 0.27 & 0.28 & 0.28 & 0.27 & 0.27 & 0.27 & 0.27 \\
\hline $\mathrm{Vp} / \mathrm{Vs}$ & 1.83 & 1.76 & 1.81 & 1.81 & 1.76 & 1.79 & 1.76 & 1.79 \\
\hline
\end{tabular}

sísmicas intracorticales, a profundidades promedio de 12 y $28 \mathrm{~km}$, aproximadamente. Las mismas podrían atribuirse a niveles de despegue (decóllements) en la región de corteza media dentro del ambiente de las Sierras Pampeanas Occidentales y tendrían continuidad lateral hacia la Precordillera (Ammirati et al., 2016). La capa comprendida desde la superficie hasta los $12 \mathrm{~km}$ de profundidad presenta velocidades promedio Vp de $5.71 \mathrm{~km} / \mathrm{s}$ y Vs de $3.39 \mathrm{~km} / \mathrm{s}$, que corresponden con una composición intermedia (tonalitas/metatonalitas). Mientras que la capa comprendida entre 18 y $28 \mathrm{~km}$ de profundidad indican
Vp aproximada de $5.85 \mathrm{~km} / \mathrm{s}$ y Vs promedio de $3.56 \mathrm{~km} / \mathrm{s}$, y corresponden con una composición más félsica (granitos, granodioritas). Valores Vp promedio de $6.64 \mathrm{~km} / \mathrm{s}$ y Vs promedio de $3.78 \mathrm{~km} / \mathrm{s} \mathrm{se}$ obtuvieron para la zona profunda de la corteza, cercana a la discontinuidad de Mohorovičić, y serían atribuibles a rocas de composición máfica (metagabros, anfibolitas, granulitas máficas). El espesor total de corteza determinado, refinando el análisis de función del receptor, es de unos 55 a $60 \mathrm{~km}$, mayor al estimado por Gallardo (2011) bajo las SVF-LH y por Perarnau et al. (2010) en zonas contiguas como la

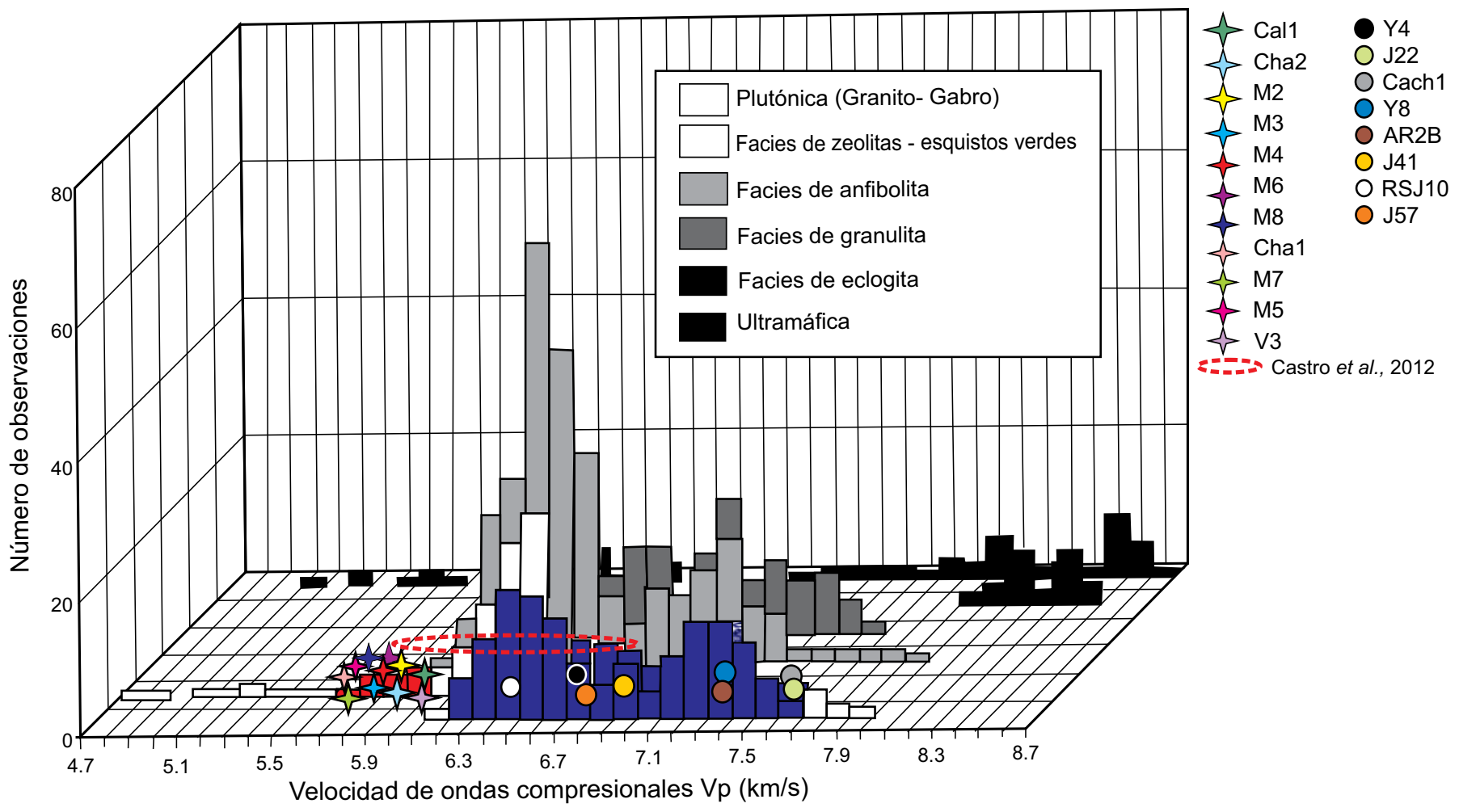

Figura 5. Velocidades de ondas P obtenidas en este estudio (Tablas 1 y 2) para rocas granitoides (barras rojas) y gabroides (barras violetas) comparadas con aquellas de rocas ígneas plutónicas (granito-gabro), metamórficas de varias facies y ultramáficas estudiadas por Christensen y Mooney (1995). Se destacan las bajas velocidades sísmicas para las litologías granitoides con respecto a los valores más elevados de las litologías máficas. El óvalo entrecortado (rojo) indica velocidades Vp halladas por Castro et al. (2012) para el extremo suroeste de la Sierra de Pie de Palo (véase su ubicación en la Figura 1). 
Sierra de Pie de Palo, utilizando la técnica de funciones del receptor y tomografía sísmica regional (Alvarado et al., 2007; Marot et al., 2014; Venerdini et al., 2016).

Nuestra investigación indica una corteza engrosada de más de $14 \mathrm{~km}$ por encima del espesor promedio de $\sim 41 \mathrm{~km}$ establecido por Christensen y Mooney (1995) y Christensen (1996) para zonas continentales activas, de composición mayormente enriquecida en cuarzo por la abundancia de granitos y granodioritas en los continentes. Por otra parte, los valores obtenidos indican la presencia de rocas de composición más máfica en contraposición con las observaciones globales, pero muy comparables con los resultados encontrados en las Sierras Pampeanas Occidentales por Calkins et al. (2006), Alvarado et al. (2009) y Castro de Machuca et al. (2012b). Nuestros resultados para las SVF-LH ponen en evidencia diferencias con las Sierras Pampeanas Orientales (Sierras de Córdoba), donde se ha identificado una corteza adelgazada respecto al promedio global, que varía de 38 a $35 \mathrm{~km}$ de espesor de oeste a este, y que está enriquecida en rocas de composición granítica (Perarnau et al., 2012; Alvarado et al., 2014).

Por debajo de la placa Sudamericana que contiene a la corteza de Cuyania, se observa la subducción de la placa de Nazca que contiene la dorsal de Juan Fernández (JFR, Juan Fernández Ridge) a profundidades cercanas a los $100 \mathrm{~km}$ (Figuras 1 y 6). Esto generaría un fuerte acoplamiento litosférico (Gutscher et al., 2000 y Alvarado et al., 2009), en una zona donde se ha observado por tomografía sísmica de ondas de cuerpo, además, la presencia de un manto frío, deshidratado y de composición rica en magnesio (Wagner et al., 2005). Estas condiciones favorecen el engrosamiento en la zona de compresión y la transferencia de esfuerzos hacia el este de la región de subducción horizontal, donde se manifiesta el levantamiento del basamento que conforma las Sierras Pampeanas, a distancias de 450 $\mathrm{km}$ al este de la trinchera para las SVF-LH, y de $800 \mathrm{~km}$ para las Sierras de Córdoba. La reinterpretación de líneas sísmicas profundas de reflexión adquiridas por la empresa Yacimientos Petrolíferos Fiscales en la década de 1980 en la cuenca del Bermejo, al oeste de la Sierra de La Huerta, por Zapata y Allmendinger (1996), Zapata (1998), Snyder et al. (1990), dan cuenta de la presencia de zonas de despegue a niveles de basamento que duplican niveles. Estas zonas se asocian a estructuras pre-andinas formadas durante el Proterozoico y Fanerozoico, actuando
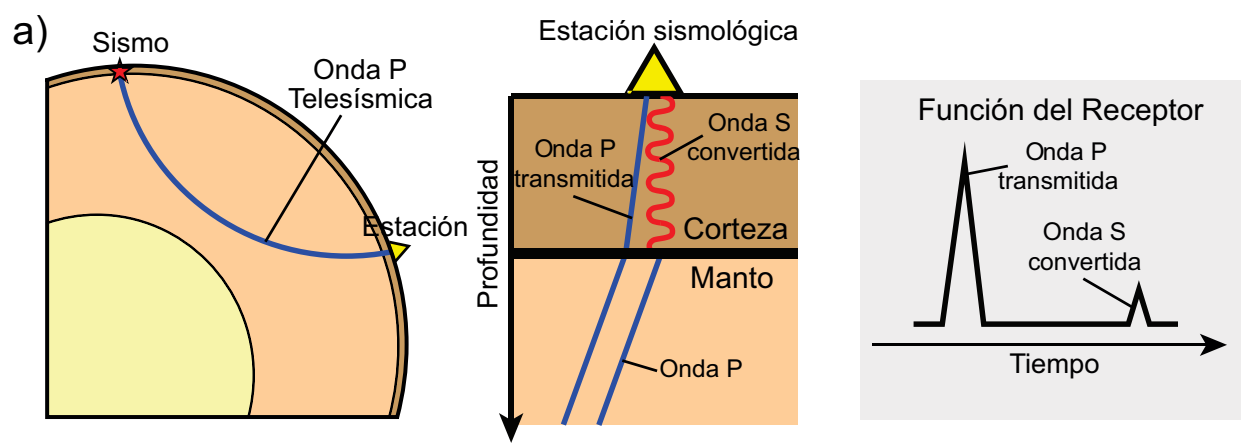

b)

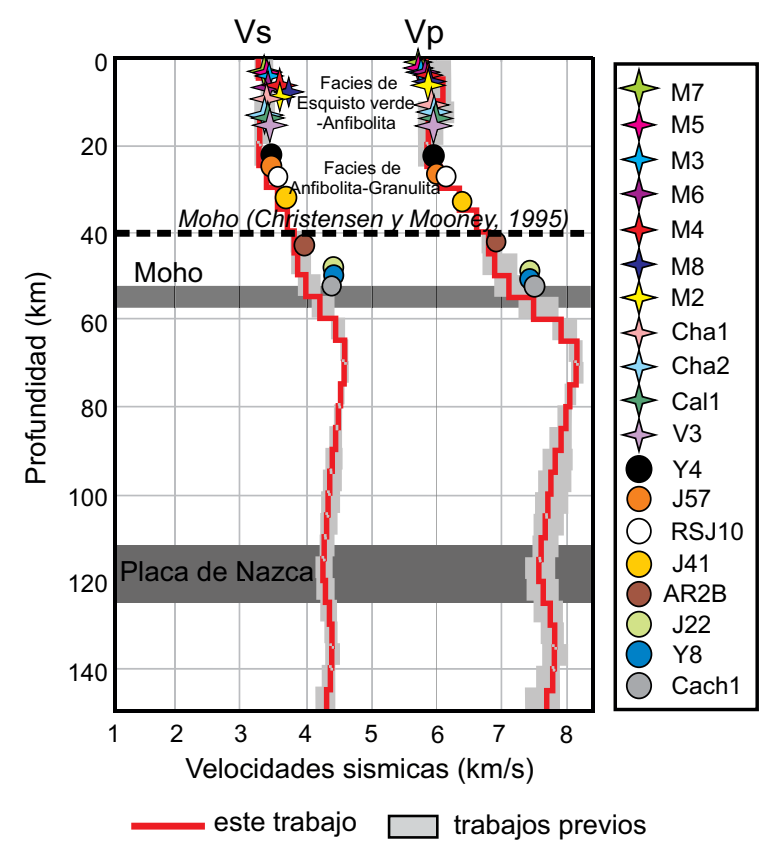

Figura 6. a) Esquema que muestra la técnica de función del receptor registrada bajo una estación sismológica para un telesismo. La diferencia entre los tiempos de arribo de la onda $\mathrm{P}$ transmitida y $\mathrm{S}$ convertida, junto con características de ambos arribos permiten determinar un modelo sísmico de la corteza. b) Modelo promedio de velocidades sísmicas de las SVF-LH a partir del análisis de formas de ondas sísmicas con función del receptor calibrado con observaciones petrológicas. Superpuesta en gris se muestra una ventana de velocidades correspondiente a los tres modelos de velocidades obtenidos para cada una de las estaciones sismológicas de la SVF-LH mencionadas en el presente estudio. Se indica la profundidad de la discontinuidad de Mohorovičić promedio para regiones continentales (Christensen y Mooney, 1995). Superpuestos, se muestran las facies y los rangos de velocidades Vp y Vs obtenidos a partir del análisis petrográfico (Tablas 1 y 2 , y Figura 5). 

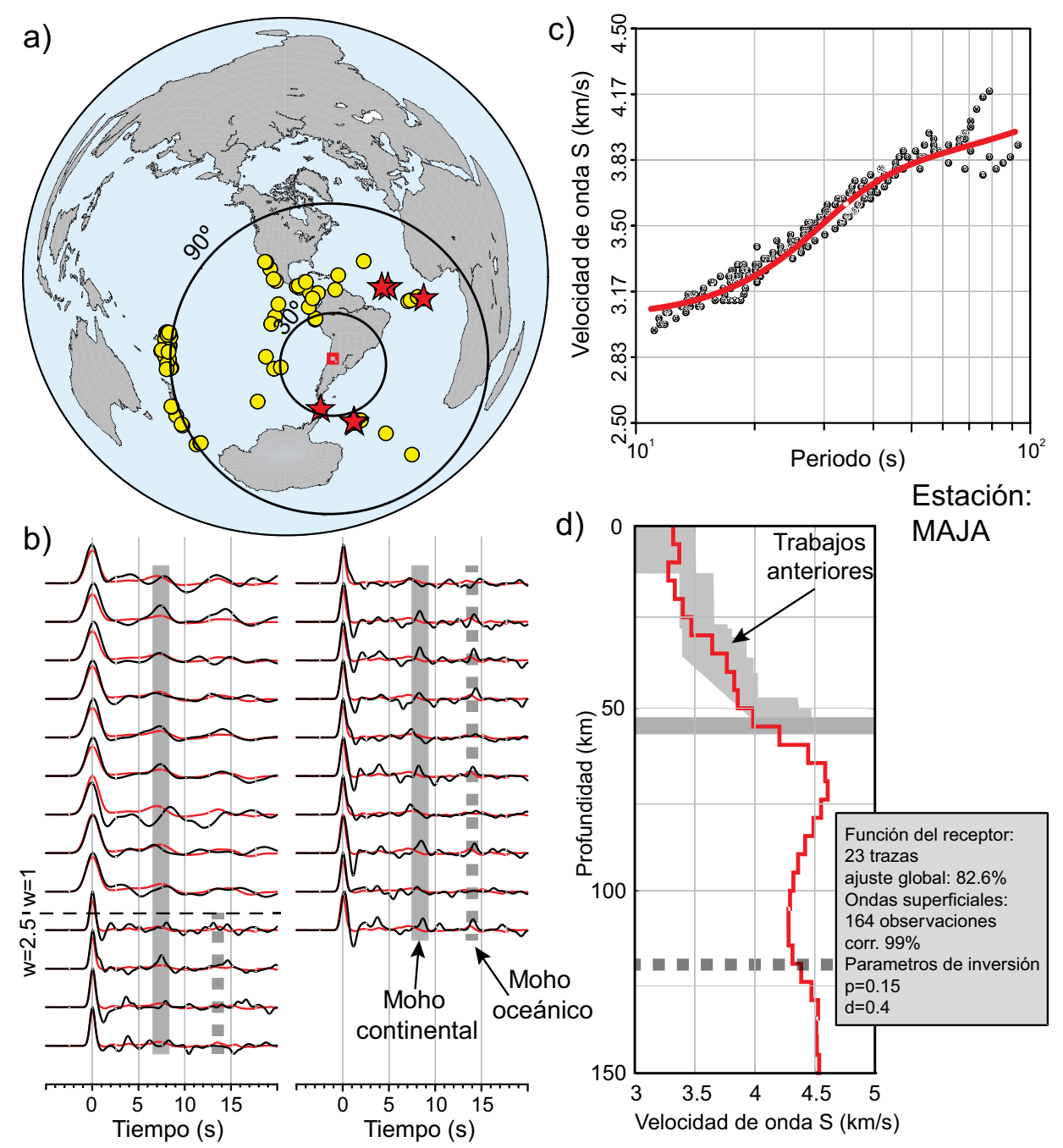

Figura 7. Resultados de la inversión conjunta de funciones del receptor y dispersión de la velocidad de fase de ondas Rayleigh para la estación MAJA. a) Mapa mostrando la localización epicentral de los telesismos utilizados para calcular las funciones del receptor (círculos amarillos) y la dispersión de ondas Rayleigh (estrellas rojas). b) Mejor ajuste entre funciones del receptor observadas (negro) y sintéticos (rojos). c) Mejor ajuste para los datos de dispersión de ondas superficiales. Los puntos negros son las observaciones y la curva roja, el mejor ajuste. d) Modelo de velocidad obtenido. En gris se muestra una ventana de velocidades obtenidas en trabajos anteriores (Alvarado et al., 2007; Perarnau et al., 2010; Venerdini et al., 2016); $p$ define el peso de las ondas superficiales en el resultado final; $d$ es el "damping" elegido.

como niveles de despegue andinos actuales. La falla de Valle Fértil, interpretada como un corrimiento con inclinación hacia el este, que alcanza los $30 \mathrm{~km}$ de profundidad (Jordan y Allmendinger, 1986, Zapata 1998), favorecería el engrosamiento cortical de las Sierras Pampeanas Occidentales en esta región.

\section{CONCLUSIONES}

El análisis petrológico de las litologías representativas del basamento cristalino del borde oriental de las SVF-LH permitió identificar granitos, granodioritas, tonalitas, dioritas, gabros, anfibolitas y granulitas máficas, con paragénesis de grado medio a alto de metamorfismo (facies de anfibolitas de alto grado a facies de granulitas). Las estimaciones de sus propiedades geofísicas indican niveles de corteza superior y media-inferior. A partir de estos valores se ha elaborado un modelo de corteza 1D de mayor detalle para este sector de las Sierras Pampeanas Occidentales, localizado en el retroarco andino por encima de la región de subducción horizontal de la placa de Nazca. Los datos experimen- tales indican que las diferencias en la composición mineralógica y el grado de metamorfismo experimentado por las rocas, con presencia de minerales hidroxilados (hornblenda y biotita) en facies de grado medio (anfibolita) y aparición de minerales anhidros (ortopiroxeno y clinopiroxeno) en facies de alto grado (granulita), influyen en las variaciones de las velocidades sísmicas. Así, se observaron valores promedio de Vp $5.80 \mathrm{~km} / \mathrm{s}$, Vs $3.39 \mathrm{~km} / \mathrm{s}$, densidad $2.66 \mathrm{~g} / \mathrm{cm}^{3}$ y coeficiente de Poisson 0.24 , para las rocas granitoides, en contraposición a valores promedios de Vp $6.76 \mathrm{~km} / \mathrm{s}$, Vs $3.77 \mathrm{~km} / \mathrm{s}$, densidad $3.005 \mathrm{~g} / \mathrm{cm}^{3}$ y coeficiente de Poisson 0.27, para las rocas de composición máfica de esta zona. Se hallaron dos capas con discontinuidades en sus propiedades geofísicas a $12 \mathrm{~km}$ y $28 \mathrm{~km}$ de profundidad, apoyadas sobre un substrato rocoso de mayor velocidad. Este substrato se extiende hasta $\sim 60 \mathrm{~km}$ de profundidad, donde se registraron velocidades de ondas $\mathrm{Vp}$ superiores a $7 \mathrm{~km} / \mathrm{s}$, que se interpreta como valores correspondientes a corteza inferior. El espesor determinado para la corteza que varía entre 55 a $60 \mathrm{~km}$ es mayor que el espesor "normal" de la corteza continental estimado en $41 \mathrm{~km}$ (Christensen y Mooney, 1995). Una corteza similar, de naturaleza máfica y mayor espesor $(\sim 66 \mathrm{~km})$ ha sido determinada 
por Pérez-Luján et al. (2015) para la Precordillera Occidental andina. Estos resultados sugieren que el terreno Cuyania en la región de subducción horizontal de la placa de Nazca presenta mayor engrosamiento cortical debido al régimen compresional, favorecido por la geometría particular de la losa subducida en posición horizontal, a $100 \mathrm{~km}$ de profundidad aproximadamente. En las SVF-LH la corteza superior presenta una composición promedio compatible con rocas plutónicas félsicas (tonalitas a granitos), que se contrapone con aquella de la corteza inferior cuya composición promedio es homologable a la de una roca intrusiva máfica (gabro) que estaría parcialmente eclogitizada; esto ha sido sugerido por otros autores para la corteza inferior de la Sierra de Pie de Palo y la Precordillera Occidental (Gilbert et al., 2006; Calkins et al., 2006; Castro de Machuca et al., 2012b; Ammirati et al., 2015; Pérez-Luján, 2015; Venerdini et al., 2016), lo cual representaría una característica de la base del terreno Cuyania.

\section{AGRADECIMIENTOS}

Este trabajo ha sido financiado por el Fondo Nacional de Ciencia y Tecnología de Argentina (PICT2011-160), becas CIN de Estímulo a las Vocaciones Científicas (2012) y de Estudiantes Avanzados de la UNSJ (2013) otorgadas a M.F. Ahumada.

\section{REFERENCIAS}

Alvarado, P., Beck, S., Zandt, G., 2007, Crustal structure of the south-central Andes Cordillera and backarc region from regional waveform modelling: Geophysical Journal International, 170(2), 858-875.

Alvarado, P., Pardo, M., Gilbert, H., Miranda, S., Anderson, M., Saez, M., Beck, S., 2009, Flat-slab subduction and crustal models for the seismically active Sierras Pampeanas region of Argentina, en Kay, S., Ramos, V. y Dickinson, W. (eds.), Backbone of the Americas: Shallow subduction, plateau uplift, and ridge and terrane collision: Boulder, Colorado, Geological Society of America Memoir, 204, 261-278.

Alvarado, P., Ortiz, G., Perarnau, M., Saez, M., Anderson, M., Gilbert, H., Pechuan, S., Martino, R.D., 2014, Sismicidad y estructura de corteza de las Sierras de Córdoba, (resumen), en $19^{\circ}$ Congreso Geológico Argentino, Simposio de Tectónica Andina: Córdoba, Argentina, Actas, S22-2.

Ammirati, J.B., Alvarado, P., Beck, S., 2015, A lithospheric velocity model for the flat slab region of Argentina from joint inversion of Rayleigh wave phase velocity dispersion and teleseismic receiver functions: Geophysical Journal International, 202(1), 224-241.

Ammirati, J.B., Pérez-Luján, S., Alvarado, P., Beck, S., Rocher, S., Zandt, G., 2016, High-resolution images above the Pampean flat slab of Argentina $\left(31-32^{\circ} \mathrm{S}\right)$ from local receiver functions: Implications on regional tectonics: Earth and Planetary Science Letters, 450, 29-39.

Anderson, M., Alvarado, P., Zandt, G., Beck, S., 2007, Geometry and brittle deformation of the subducting Nazca plate, central Chile and Argentina: Geophysical Journal International, 171(1), 419-434.

Astini, R.A., Thomas, W.A., 1999, Origin and evolution of the Precordillera terrane of western Argentina: a drifted Laurentian orphan, en Ramos, V.A., Keppie, J.D. (eds.), Laurentia-Gondwana connections before Pangea: Boulder, Colorado, Geological Society of America Special Paper, 336, 1-20.

Baldis, B., Martínez, R., Villegas, C., Pereyra, M.E., Pérez, A.M., 1990, Estructura, provincialismo geológico y unidades tectonoestratigráficas de San Juan, en $10^{\circ}$ Congreso Geológico Argentino, Geología y Recursos Naturales de la Provincia de San Juan: San Juan, Argentina, Relatorio, 186-211.

Baldo, E., Saavedra, J., Rapela, C., Pankhurst, R., Casquet, C., Galindo, C., 1997, Síntesis geocronológica de la evolución paleozoica inferior del borde sur de Gondwana en las Sierras Pampeanas, Argentina: Acta Geológica Hispana, 32(1), 17-28.

Barazangi, M., Isacks, B., 1976, Spatial distribution of earthquakes and subduction of the Nazca plate beneath South America: Geology, 4(11), 686-692
Brocher, T., 2005, Empirical relations between elastic wave speeds and density in the Earth's crust: Bulletin of the Seismological Society of America, 95, 2081-2092.

Cahill, T., Isacks, B., 1992, Seismicity and shape of the subducted Nazca plate: Journal of Geophysical Research, 97(B12), 17503-17529.

Calkins, J., Zandt, G., Gilbert, H., Beck, S., 2006, Crustal images from San Juan, Argentina, obtained using high frequency local event receiver functions: Geophysical Research Letters, 33(7), 1-4.

Caminos, R., 1979, Sierras Pampeanas Noroccidentales. Salta, Tucumán, Catamarca, La Rioja y San Juan, en Leanza, E.F. (ed.), II Simposio de Geología Regional Argentina: Córdoba, Argentina, Academia Nacional de Ciencias, Acta, 1, 225-291.

Castro de Machuca, B., Arancibia, G., Morata, D., Belmar, M., Pontoriero, S., Previley, L., 2005, Transformaciones texturales, mineralógicas y químicas en metagabros afectados por cizallamiento dúctil, Sierra de La Huerta, San Juan, Argentina, en $16^{\circ}$ Congreso Geológico Argentino: La Plata, Argentina, Actas, 1, 907-914.

Castro de Machuca, B., Arancibia, G., Previley, L., Pontoriero, S., Morata, D., 2008, Ordovician mylonites from Mesoproterozoic granitoid, Sierra de Pie de Palo, Western Sierras Pampeanas, San Juan Province, en $6^{\text {th }}$ South American Symposium on Isotope Geology: San Carlos de Bariloche, Argentina, Disco Compacto.

Castro de Machuca, B., Delpino, S., Previley, L., Mogessie, A., Bjerg, E., 2012a, Tectono-metamorphic evolution of a high- to medium-grade ductile deformed metagabbro/metadiorite from the Arenosa Creek Shear Zone, Western Sierras Pampeanas, Argentina: Journal of Structural Geology, $42,261-278$.

Castro de Machuca, B., Perarnau, M., Alvarado, P., López, G., Saez, M., 2012b, A seismological and petrological crustal model for the southwest of the Sierra de Pie de Palo, Province of San Juan: Revista de la Asociación Geológica Argentina, 69(2), 177-184.

Christensen, N., 1996, Poisson's ratio and crustal seismology: Journal of Geophysical Research, 101(B2), 3139-3156.

Christensen, N., Mooney, W., 1995, Seismic velocity structure and composition of the continental crust: a global view: Journal of Geophysical Research, 100(B7), 9761-9788.

Gallardo, G., 2011, Determinación de la estructura de velocidades sísmicas a partir de la función del receptor en el flanco oriental de las Sierras de Valle Fértil-La Huerta: San Juan, Argentina, Universidad Nacional de San Juan, Argentina, trabajo final de licenciatura en Geofísica, $86 \mathrm{pp}$.

Gans, C., Beck, S., Zandt, G., Gilbert, H., Alvarado, P., Anderson, M., Linkimer, L., 2011, Continental and oceanic crustal structure of the Pampean flat slab region, western Argentina, using receiver function analysis: new high-resolution results: Geophysical Journal International, 186(19), 45-58.

Gilbert, H., Beck, S., Zandt, G., 2006, Lithospheric and upper mantle structure of Central Chile and Argentina: Geophysical Journal International, 165(1), 383-398.

Giménez, M.E., Martínez M.P., Introcaso, A., 2000, A crustal model based mainly on gravity data in the area between the Bermejo Basin and the Sierra de Valle Fértil, Argentina: Journal of South American Earth Sciences, 13(3), 275-286.

González-Bonorino, F., 1950, Algunos problemas geológicos de las Sierras Pampeanas: Revista de la Asociación Geológica Argentina, 16(3), 81-110.

Gutscher, M., Spakman, W., Bijwaard, H., Engdahl, R., 2000, Geodynamics of flat subduction: Seismicity and tomographic constraints from the Andean margin: Tectonics, 19(5), 814-833.

Hacker, B.R., Abers, G.A., 2004, Subduction Factory 3, An Excel worksheet and macro for calculating the densities, seismic wave speeds, and $\mathrm{H}_{2} \mathrm{O}$ contents of minerals and rocks at pressure and temperature: Geochemistry, Geophysics, Geosystems, 5(1), DOI 10.1029/2003GC000614.

Herrmann, R.B., 1973, Some aspects of band-pass filtering of surface waves: Bulletin of the Seismological Society of America, 63, 703-711.

Herrmann, R.B., Ammon, C.J., 2002. Computer programs in seismology-3.30: surface waves, receiver functions and crustal structure: www.eas.slu.edu/ People/RBHerrmann/CPS330.html, Consultado en febrero 2017.

Jordan T.E., Allmendinger, R.W., 1986, The Sierras Pampeanas of Argentina: a modern analogue of Laramide deformation: American Journal of Science, 286(10), 737-764.

Julià, J., Ammon, C.J., Herrmann, R.B., Correig, A.M., 2000, Joint inversion of 
receiver function and surface wave dispersion observations: Geophysical Journal International, 143, 99-112.

Kendrick, E., Bevis, M., Smalley, R., Brooks, B., Vargas, R.B., Laurıa, E., Fortes, L.P.S., 2003, The Nazca-South America Euler vector and its rate of change: Journal of South American Earth Sciences, 16(2), 125-131.

Langston, C.A., 1979, Structure under Mount Rainier, Washington, inferred from teleseismic body waves: Journal of Geophysical Research, 84(B9), 4749-4762.

Lince, F., Croce, F., Giménez, M., Martínez, P., 2008, Delimitación de cuerpos plutónicos, en el sector nororiental del macizo Norpatagónico, a partir de datos gravimétricos, en $17^{\circ}$ Congreso Geológico Argentino: Jujuy, Argentina, Actas, III, 1096-1097.

Marot, M., Monfret, T., Gerbault, M., Nolet, G., Ranalli, G., Pardo, M., 2014, Flat versus normal subduction zones: a comparison based on 3-D regional traveltime tomography and petrological modelling of central Chile and

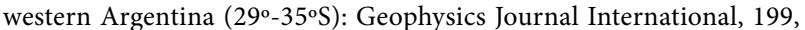
1633-1654.

McMechan, G.A., Yeldin, J., 1981, Analysis of dispersive waves by wave field transformation: Geophysics, 46, 869-874.

Miller, H., Söllner, F., 2005, The Famatina complex (NW Argentina): backdocking of an island arc or terrane accretion? Early Palaeozoic geodynamics at the western Gondwana margin: Geological Society of London Special Publications, 246(1), 241-256.

Mirré, J.C., 1976, Descripción Geológica de la Hoja 19e, Valle Fértil, Provincias de San Juan y La Rioja: Buenos Aires, Argentina, Servicio Geológico Nacional, Boletín No. 147, 70 pp.

Mokthar, T., Herrmann, R.B., Russell, D.R., 1988, Seismic velocity and Q model for the shallow structure of the Arabian shield from short-period Rayleigh waves: Geophysics, 53, 1379-1387.

Ortiz, G., Fosdick, J., Alvarado, P., 2014, Edades termocronológicas en las sierras de Valle Fértil - La Huerta: resultados preliminares de dataciones (U-Th)/He en apatitos, en $19^{\circ}$ Congreso Geológico Argentino, Simposio de Tectónica Andina, Córdoba, Argentina: Actas, S20-22.

Ortiz, G., Alvarado, P., Fosdick, J.C., Perucca, L., Saez, M., Venerdini, A., 2015, Active deformation in the northern Sierra de Valle Fértil, Sierras Pampeanas, Argentina: Journal of South American Earth Sciences, 64(2), 339-350.

Otamendi, J.E., Demichelis, A.H., Tibaldi, A.M., De la Rosa, J.D., 2006, Genesis of aluminous and intermediate granulites; a case study in the eastern Sierras Pampeanas, Argentina: Lithos, 89(1-2), 66-88.

Otamendi, J.E., Tibaldi, A.M., Vujovich, G.I., Viñao, G.A., 2008, Metamorphic evolution of migmatites from the deep Famatinian arc crust exposed in Sierras Valle Fértil-La Huerta, San Juan, Argentina: Journal of South American Earth Sciences, 25, 313-335.

Otamendi, J.E., Vujovich, G.I., de la Rosa, J.D., Tibaldi, A.M., Castro, A., Martino, R.D., Pinotti, L.P., 2009, Geology and petrology of a deep crustal zone from the Famatinian paleoarc, Sierras de Valle Fértil and La Huerta, San Juan, Argentina: Journal of South American Earth Sciences, 27, 258-279.

Perarnau, M., Alvarado, P., Saez, M., 2010, Estimación de la estructura cortical de velocidades sísmicas en el suroeste de la Sierra de Pie de Palo, provincia de San Juan (Argentina): Revista de la Asociación Geológica Argentina, 67(4), 473-480.

Perarnau, M., Gilbert, H., Alvarado, P., Martino, R., Anderson, M., 2012, Crustal structure of the Eastern Sierras Pampeanas of Argentina using high frequency receiver functions: Tectonophysics, 580, 208-217, DOI 10.1016/j.tecto.2012.09.02.1.

Pérez-Luján, S.B., Ammirati, J.B., Alvarado, P., Vujovich, G., 2015, Constraining a mafic thick crust model in the Andean Precordillera of the Pampean flat slab subduction region: Journal of South American Earth Sciences, 64(2), 325-338.

Ramos, V.A., 1988, Tectonics of the Late Proterozoic-Early Paleozoic: a collisional history of southern South America: Episodes, 11(3), 168-174.

Ramos, V.A., 1995, Sudamérica: un mosaico de continentes y océanos: Ciencia Hoy, 6 (32), 24-29.

Ramos, V.A., Vujovich, G.I., Dallmeyer, R.D., 1996, Los klippes y ventanas tectónicas de la estructura preándica de la Sierra de Pie de Palo (San Juan): edad e implicaciones tectónicas, en $13^{\circ}$ Congreso Geológico Argentino y $3^{\circ}$ Congreso de Exploración de Hidrocarburos, Buenos Aires, Argentina: Actas, 5, 377-392.
Ramos, V.A., Dallmeyer, R.D., Vujovich, G., 1998, Time constraints on the Early Palaeozoic docking of the Precordillera, central Argentina, en Pankhurst, R.J., Rapela, C.W. (eds.), The Proto-Andean Margin of Gondwana: Geological Society of London Special Publications, 142, 143-158.

Ramos, V.A., Cristallini, E.O., Pérez, D.J., 2002, The Pampean flat-slab of the central Andes: Journal of South American Earth Sciences, 15(1), 59-78.

Ramos, V.A., 2010, The tectonic regime along the Andes: Present settings as a key for the Mesozoic regimes: Geological Journal, 45, 2-25.

Rapela, C.W., Pankhurst, R.J., Casquet, C., Baldo, E., Saavedra, J., Galindo, C., 1998, Early evolution of the Proto-Andean margin of South America: Geology, 26(8), 707-710.

Rapela, C.W., Pankhurst, R.J., Baldo, E.G., Casquet, C., Galindo, C., Fanning, C.M., Saavedra, J., 2001, Ordovician metamorphism in the Sierras Pampeanas: new U-Pb SHRIMP ages in central-east Valle Fértil and Velasco Batholith, en $3^{\text {rd }}$ International Symposium on South American Isotope Geology: Pucón, Chile, Extended Abstracts, 616-619, Disco Compacto.

Rapela, C.W., Pankhurst, R.J., Casquet, C., Fanning, C.M., Baldo, E.G., González Casado, J.M., Galindo, C., Dahlquist, J., 2007, The Río de la Plata Craton and the assembly of SW Gondwana: Earth Science Reviews, 83(1), 49-82.

Snyder, D.B., Ramos, V.A., Allmendinger, R.W., 1990, Thick-skinned deformation observed on deep seismic reflection profiles in western Argentina: Tectonics, 9(4), 773-788.

Steenken, A., Werner, K., López de Luchi, M.G., Siegesmund, S., Pawlig, S., 2004, Crustal provenance and cooling of the basement complexes of the Sierra de San Luis: an insight into the tectonic history of the Proto-Andean margin of Gondwana: Gondwana Research, 7(4), 1171-1195.

Tibaldi, A.M., Otamendi, J.E., Cristofolini, E.A., Vujovich, G.I., Martino, R.D., 2009, Condiciones físicas de formación de gabros y migmatitas derivadas de rocas máficas en el centro de la Sierra de Valle Fértil, San Juan: Revista de la Asociación Geológica Argentina, 65(3), 487-503.

Thomas, W.A., Astini, R.A., 1996, The Argentine Precordillera: A traveler from the Ouachita embayment of North American Laurentia: Science, 273(5276), 752-757.

Venerdini, A., Sánchez, G., Alvarado, P., Bilbao, I., Ammirati, J., 2016, Nuevas determinaciones de velocidades de ondas $\mathrm{P}$ y ondas $\mathrm{S}$ para la corteza sísmica del terreno Cuyania en el retroarco andino: Revista Mexicana de Ciencias Geológicas, 33(1), 59-71.

Vigny, C., Rudloff, A., Ruegg, J.C., Madariaga, R., Campos, J., Alvarez, M, 2009, Upper plate deformation measured by GPS in the Coquimbo gap, Chile: Physics of the Earth and Planetary Interiors, 175(1-2), 86-95.

Vujovich, G.I., van Staal, C.R., Davis, W., 2004, Age constraints on the tectonic evolution and provenance of the Pie de Palo Complex, Cuyania composite terrane, and the Famatinian Orogeny in the Sierra de Pie de Palo, San Juan, Argentina: Gondwana Research, 7(4), 1041-1056.

Wagner, L., Beck, S., Zandt, G., 2005, Upper mantle structure in the southcentral Chilean subduction zone ( $30^{\circ}$ to $\left.36^{\circ} \mathrm{S}\right)$ : Journal of Geophysical Research, 110(B1), 1-20.

Yañez, G., Ranero, G.R., Huene, R., von Díaz, J., 2001, Magnetic anomaly interpretation across a segment of the Southern Central Andes $\left(32-34^{\circ} \mathrm{S}\right)$ : implications on the role of the Juan Fernández Ridge in the tectonic evolution of the margin during upper Tertiary: Journal of Geophysical Research, 106(4), 6325-6345.

Zandt, G., Ammon, C.J., 1995, Continental crust composition constrained by measurements of crustal Poisson's ratio: Nature, 374(6518), 152-154.

Zapata, T.R., 1998, Crustal structure of the Andean thrust front at $30^{\circ} \mathrm{S}$ latitude from shallow and deep seismic reflection profiles, Argentina: Journal of South American Earth Sciences, 11(2), 131-151.

Zapata, T.R., Allmendinger, R.W., 1996, Thrust front zone of the Precordillera, Argentina: a thick skinned triangle zone: Bulletin of the American Association of Petroleum Geologists, 80(3), 350-381.

Zippi, P.A., 1992, Counter PC 1.0 software, SN 1-S-0013: Eagle River, Alaska, United States of America, Programa de cómputo.

Manuscrito recibido: agosto 24, 2016

Manuscrito corregido recibido: noviembre 18, 2016

Manuscrito aceptado: noviembre 24, 2016 